\title{
Consistency of observed winter precipitation trends in northern Europe with regional climate change projections
}

\author{
Jonas Bhend · Hans von Storch
}

Received: 15 May 2007/ Accepted: 23 October 2007/Published online: 4 December 2007

(C) The Author(s) 2007

\begin{abstract}
Often it is claimed that the recent changes in northern European climate are at least partly anthropogenic even though a human influence has not yet been successfully detected. Hence we investigate whether the recent changes are consistent with regional climate change projections. Therefore, trends in winter (DJF) mean precipitation in northern Europe are compared to human induced changes as predicted by a set of four regional climate model simulations. The patterns of recent trends and predicted changes match reasonably well as indicated by pattern correlation and the similarity is very likely not random. However, the model projections generally underestimate the recent change in winter precipitation. That is, the signal-to-noise ratio of the anthropogenic precipitation change is either rather low or the presently used simulations are significantly flawed in their ability to project changes into the future. European trends contain large signals related to the North Atlantic Oscillation (NAO), of which a major unknown part may be unrelated to the anthropogenic signal. Therefore, we also examine the consistency of recent and projected changes after subtracting the NAO signal in both the observations and in the projections. It turns out that even after the removal of the
\end{abstract}

J. Bhend $(\varangle) \cdot$ H. von Storch

Institute for Coastal Research, GKSS-Research Centre,

Max-Planck-Strasse 1, 21502 Geesthacht, Germany

e-mail: jonas.bhend@gkss.de

\section{J. Bhend}

International Max Planck Research School on Earth System

Modelling, Hamburg, Germany

H. von Storch

Meteorological Institute, University of Hamburg,

Hamburg, Germany
NAO signal, the pattern of trends in the observations is similar to those projected by the models. At the same time, the magnitude of the trends is considerably reduced and closer to the magnitude of the change in the projections.

Keywords Detection and attribution - Climate change . Precipitation · Regional climate models · Northern Europe

\section{Introduction}

When asking for proof of anthropogenic effects on our changing climate, usually "detection and attribution studies" are sought after (Hasselmann 1993, 1997; Allen and Tett 1999). That is, one first asks if the most recent changes are within the range of internal climate variability (Hegerl et al. 2007; Barnett et al. 2005). This detection step does not lead to the identification of a specific forcing, thus a further step-the "attribution"-is needed. This is to determine the most plausible mix of causes, which explains best the once detected external forcing.

In the regional view, the formal detection and attribution has rarely been done (e.g., for France, Spagnoli et al. 2002; for Europe, Zwiers and Zhang 2003 and Stott 2003). This is related to the fact that the signal-to-noise ratio decreases when the area becomes smaller (Stott and Tett 1998). Thus, it is not surprising that the Baltex Assessment of Climate Change for the Baltic Sea Basin (BACC) failed to find any formal detection and attribution attempts (BACC author team 2008); instead, most analyses were examining whether "significant" trends would prevail. Obviously, this approach is mislead by an inadequate connotation of the term "significant", which is sometimes falsely understood as proof for detection. Instead, a significant trend means nothing but that if we would observe the same period in a 
parallel world, we would again see a positive trend. This statement does not imply that the trend is improbable if only natural factors prevail, nor can we draw conclusion on the underlying mechanisms causing the change. Additionally, for formal detection we need significance of the results against natural (internal) variability. Consequently, the estimate of natural (internal) variability is the most crucial part of a detection study.

In the present paper, we pursue a different line of analysis-motivated by the missing or highly imperfect knowledge of natural variability in wintertime precipitation. We ask if the most recent trends are consistent with what contemporary regional climate models envisage as the response to increasing greenhouse gases (GHG) and changing aerosol concentrations. In this way, we offer the possibility to falsify the hypothesis of a presently observable anthropogenic signal. In this setup the recent change is (apart from uncertainties in the initial data and the preprocessing of the data) given, the response to anthropogenic forcing, however, has to be estimated. A testable hypothesis of the above research question is "observed change is drawn from the set of simulated responses to anthropogenic forcing ". However, as we have reasons to believe that the estimated responses available do not represent unbiased versions of the "true" response, we refrain from formally testing the hypothesis and collect plausibility arguments instead.

Detection, i.e. rejection of the null hypothesis of "no anthropogenic signal" would be preferable, and the possible outcome of our analysis, namely "no falsification", is less interesting but nevertheless useful. However, it is important to be aware of the limitations of our approach. Our method cannot discriminate the plausibility of different forcing-effects but merely assess the consistency of recent changes with an a priori assumed mechanism, in particular increasing levels of GHGs in the atmosphere. Furthermore, we cannot deduce a detection statement- "it is unlikely that the observed change is due to natural variability"-from a positive outcome ("anthropogenic forcing is a good explanation for the observed trend") of our analysis. Obviously, a regular "detection and attribution" analysis is more informative, but our method is applicable also in cases of considerably less data and without reference to sometimes hardly available estimates of natural variability.

If the recent trend fails to be consistent with the expected trend, then-given all assumptions are correctin principle three reasons may be thought of: The model is insufficient (the expected signal is false), the natural variability overwhelms the signal, or more than the expected mechanism is at work, for instance decreasing concentrations of industrial aerosols in parallel to an increase of GHGs. However, due to the lack of meaningful estimates of the natural climate variability and the response to competing forcing mechanisms, we are not able to discriminate between these three reasons using the analysis as presented in this publication.

We focus on wintertime (DJF) precipitation in the Baltic catchment (denoted by solid grey contours in Figs. 2, 3, and 4) and northern European land areas (e.g. Fig. 2) as we expect the largest changes due to anthropogenic forcing to occur in this season. Furthermore, we know that wintertime precipitation is mainly large scale and thus more reliably simulated by climate models.

\section{Materials and methods}

\subsection{Observations}

Trends in observation data are computed using the wellknown gridded data set of the Climatic Research Unit (CRU TS 2.1, Mitchell and Jones 2005). These fields consist of monthly precipitation totals on a $0.5 \times 0.5$ degree latitude-longitude grid available for the period from 1901 to 2002. The gridded observations have further been interpolated to the rotated latitude-longitude grid described in the next section in order to keep the effective grid box area comparable within the research domain. Trends in the observation data have been calculated using ordinary least squares linear regression.

It has been claimed that the CRU TS 2.1 data set is not suited for detection and attribution studies as the station series have not previously been homogenized and possible effects of urban development and land use changes are still present in the data. However, we expect the data to sufficiently reflect precipitation development in northern Europe during the last decades of the twentieth century due to the large number of stations entering the analysis and assuming that most of the inhomogeneities are not systematic.

\subsection{Anthropogenic climate change signal estimates}

The anthropogenic climate change signal is derived from time slice experiments with a regional climate model. Using well separated (in this case 110 years) time slices to estimate the anthropogenic climate change signal has the advantage of increasing the signal-to-noise ratio. In contrast, deriving the anthropogenic fingerprint from transient climate change simulations for the period under investigation (here 1973-2002) requires a large ensemble in order to get a noise free fingerprint. Such large ensembles of transient regional climate change experiments are not available at the moment. We try to capture the range of 
probable responses by looking at the different climate change projections, well aware of the fact that we might underestimate this range considerably.

The set of regional climate model simulations used in this paper consists of experiments run with the Rossby Centre regional Atmosphere-Ocean model (RCAO) of the Swedish Meteorological and Hydrological Institute (SMHI). These experiments have been carried out as part of the EU project PRUDENCE and are described in detail in Räisänen et al. (2004), Kjellström (2004), and references therein. The atmospheric part of the RCAO has been run on a rotated latitude-longitude grid with a grid spacing of $0.44^{\circ}$ (approximately $49 \mathrm{~km}$ ).

For each of the two different driving global models, the ECHAM4/OPYC (Roeckner et al. 1999) and HADAM3H (Gordon et al. 2000), a control run representing present day conditions (1961-1990) and two scenario runs (20712100) based on IPCC SRES A2 and B2 scenarios have been run. The regional anthropogenic change signals for the different driving GCMs and scenarios have been defined as the difference between scenario and respective control run means scaled to change per decade. As we have only two "points" along the time axis, namely the change of 30 year mean precipitation from 1961-1990 to 20712100 , we scale the projections by assuming a linear development between 1961 and 2100; the validity of this assumption is discussed at the end of this section. The signal is further scaled to change per decade. Hence, we have a set of four regional climate change projections available, which are referred to as HadAM A2 (B2) and ECHAM A2 (B2) in the following according to the driving GCM and emission scenario used.

Underlying to our analysis are several assumptions, which are listed in the following:

First, we assume that our contemporary models are good enough for projecting anthropogenic climate change. We believe that they are, but we have to acknowledge that a conclusive proof of that assumption is not possible at this time.

Second, we presume that regional climate modelsespecially when coupled with an ocean model and thus resulting in much more realistic sea surface temperatures in the Baltic Sea-provide more realistic estimates of the present and future climates in this region than GCMs do.

Third, the response to anthropogenic forcing is assumed to be linear. This is supported by the analysis of climate change projections with different GHG forcings (SRES A2 and B2) which vary mainly in magnitude (Räisänen et al. 2004). Additionally, the global mean response to anthropogenic forcing is as a first approximation linear as well (Cubasch et al. 2001).

The significance of the climate change estimates has been assessed using the lookup table test as described in
(Zwiers and von Storch 1995). This modified $t$ test takes into account that the data in the two samples (1961-1990 and 2071-2100) are autocorrelated. In order to get a conservative estimate of the autocorrelation coefficient, we have set negative autocorrelation estimates to zero. Although this test accounts for temporal interdependence of the observations, the spatial correlation is not dealt with in particular. The abovementioned test indicates whether the estimated response could be due to internal model variability. The influence of high-frequency variability is expected to be small (this is supported by the results of the adjusted $t$ test). Still, as we do not use an initial condition ensemble, we cannot quantify the influence of low-frequency variability on the climate change scenarios.

\subsection{NAO representations and NAO signals}

We use a station based NAO index, which is defined as the difference in normalized monthly sea level pressure (SLP) between Reykjavik and Gibraltar according to Jones et al. (1997). The NAO index in the set of regional climate model simulations has been derived accordingly from the respective SLP fields. The reference period for the normalization of SLP time series is 1961-1990. The variability in the dimensionless NAO index based on observations is higher than the variability based on the two different 19611990 representations in the regional model simulations with a standard deviation of 1.46 in the observations and 1.14 (1.09) in the HadAM (ECHAM) simulation.

The signal or fingerprint of the NAO is defined as the fraction of the variability in wintertime precipitation, which covaries with the NAO index. Thus, we regress the detrended precipitation time series on the detrended NAO index for each grid box separately using ordinary least squares estimation of the parameters of the linear regression. The slope of the regression is the NAO signal or fingerprint. This signal is removed from the observations by subtracting the product of the trend in the NAO index times the NAO signal from the trend in the observations. From the climate change projections, we remove the NAO fingerprint by simply subtracting the respective NAO fingerprint times the difference in the average NAO index for the periods 1961-1990 and 2071-2100.

\subsection{Comparing the patterns of change}

The comparison of recent and expected trends $R$ and $E$ may be broken down by considering the dimensionless patterns $R^{*}=\frac{R}{\|R\|}$ and $E^{*}=\frac{E}{\|E\|}$, and the norms $\|R\|$ and $\|E\|$. The latter are the intensities of the pattern and are defined as follows: 


$$
\|R\|=\sqrt{\frac{1}{n} \sum_{i=1}^{n} R_{i}^{2}} \quad\|E\|=\sqrt{\frac{1}{n} \sum_{i=1}^{n} E_{i}^{2}}
$$

The index subscript $i$ counts the spatial points $i=1, \ldots, n$.

The patterns are compared with the pattern correlation coefficient (PCC, Eq. 2), which is different from the centered pattern correlation and uncentered cross-moment introduced in Santer et al. (1993).

$\rho_{R, E}=\frac{1}{n} \sum_{i=1}^{n} R_{i}^{*} E_{i}^{*}=\frac{\sum_{i=1}^{n} R_{i} E_{i}}{\sqrt{\sum_{i=1}^{n} R_{i}^{2} \sum_{i=1}^{n} E_{i}^{2}}}$

$\rho$ is bound by 1 , i.e., $|\rho| \leq 1$. We use uncentered pattern correlation because the information about a human induced change is both in the spatial mean and the spatial variability of the pattern.

Furthermore, we use a bootstrap test to investigate the range of PCCs of randomly generated trend fields with a spatial covariance structure similar to that of precipitation trends. Therefore, we repeatedly (200 times) randomly select 30 years of winter precipitation from the 102 available years and compute the trends. We then calculate PCCs for every two different trend fields once, giving us an ensemble of 19,900 randomly generated PCCs. For this set of PCCs, we compute the percentiles. Additionally, as we know that the data might be autocorrelated, we repeat this experiment by randomly selecting groups of five and fifteen consecutive years, this technique is known as the moving blocks bootstrap (Wilks 1997). It is shown, that for both the Baltic catchment and all of northern Europe, the distribution broadens and thus the percentiles increase (see Table 1).

We use the results derived from the moving block bootstrap experiment with a block length of 5 years, however the selection of the block length is subjective. According to Wilks (1997), the appropriate block length is dependent on the autocorrelation structure of the data under investigation and should thus be derived individually at each grid point. In contrast, one should use the same block length for all variables in multivariate problems. Thus, the ideal block length cannot be computed as at least one of the two criteria is violated. However, additional analyses with

Table 1 Percentiles of PCCs of trends from randomly selected precipitation fields for the Baltic catchment and northern Europe (in brackets)

\begin{tabular}{llll}
\hline Percentiles & 95 th & 98 th & 99th \\
\hline 1 year & $0.592(0.525)$ & $0.690(0.618)$ & $0.742(0.672)$ \\
5 years & $0.623(0.568)$ & $0.718(0.666)$ & $0.769(0.721)$ \\
15 years & $0.688(0.638)$ & $0.792(0.753)$ & $0.852(0.825)$ \\
NAO removed & & & \\
5 years & $0.669(0.602)$ & $0.758(0.697)$ & $0.805(0.749)$ \\
\hline
\end{tabular}

Wilks (1997) rule for choice of the block length have shown that-assuming first order autocorrelation-no block lengths larger than four are found within the domain.

The respective histograms of PCCs for the Baltic catchment and northern Europe are shown in Fig. 1. The percentiles of the random PCCs are listed in Table 1, the uncertainties ( 2 standard deviations estimated from 20 repeats of the above experiment) for these percentile estimates range from 0.02 to 0.03 for the Baltic catchment (0.03-0.04 for northern Europe). The bootstrap estimates of random PCCs for the Baltic catchment and northern Europe after removing the NAO signal lie slightly higher as shown in the last row of Table 1 .

\section{Observed and simulated changes in winter precipitation totals}

\subsection{Trends in observation data}

We use 30-year trends in order to assess the most recent changes. On the one hand, the period under investigation should be sufficiently short, as we know from global and continental scale results, that the anthropogenic signal in temperature emerges in the last few decades from natural variability (Hegerl et al. 2007). In contrast, the influence of natural variability on the observed trend reduces with increasing trend length on the other hand.

When different trend lengths are used, the pattern remains mostly unaffected. The magnitude of the trends, however, decreases with increasing trend length due to either a reduction of the fraction of trends induced by natural variability and/or due to a weaker anthropogenic signal in the mid-twentieth century (not shown).

Figure 2 shows the 30-year changes in seasonal winter (DJF) precipitation according to the gridded CRU data. The

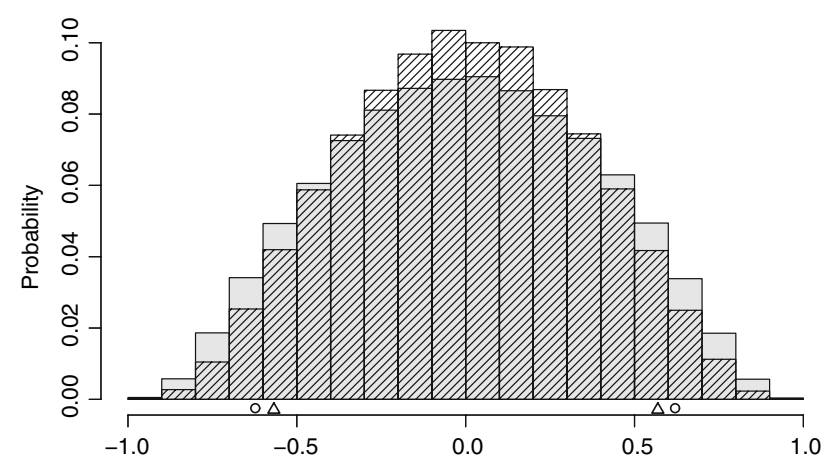

Fig. 1 Histogram of PCCs of trends of randomly selected precipitation fields. The shaded bars refer to the PCCs for the Baltic catchment, the hatched bars refer to northern European PCCs. The 5 and 95 percentiles for the Baltic catchment (northern Europe) are indicated by a circle (triangle) 


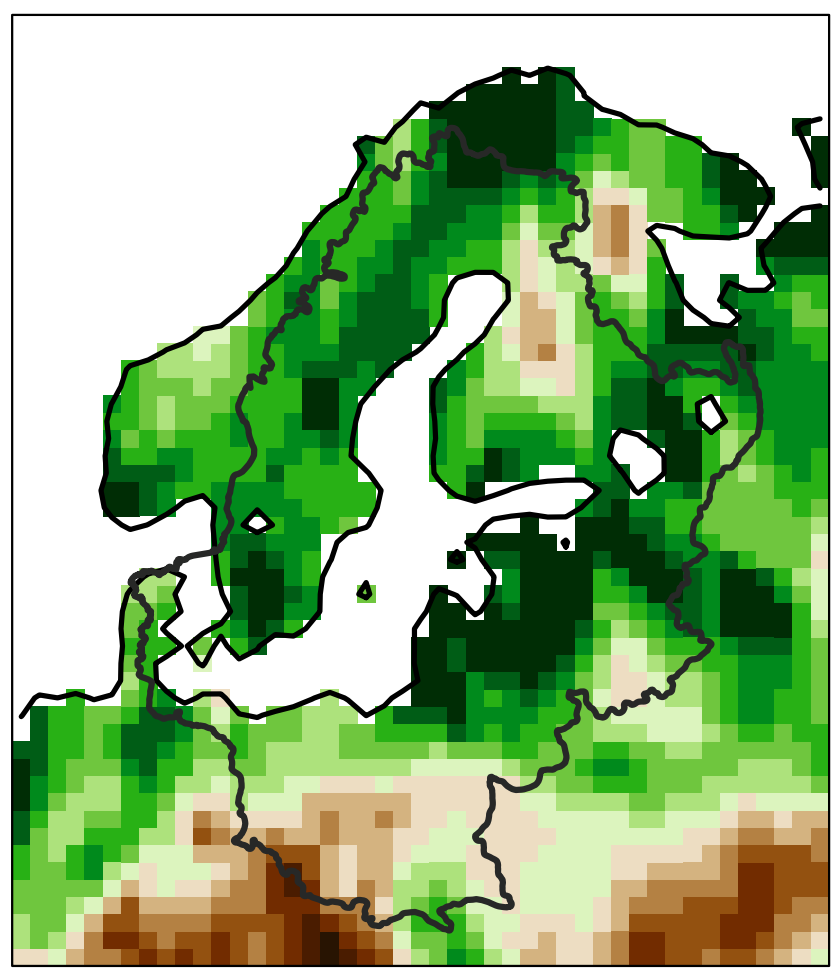

percentage of 1961-1990 mean per decade

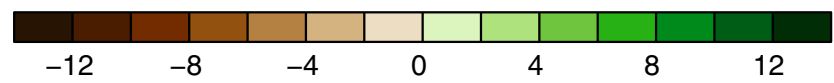

Fig. 2 Trends in winter (DJF) precipitation totals 1973-2002 in units of relative change compared to the 1961-1990 mean precipitation (according to the CRU TS 2.1 data)

pattern is a general increase over most of northern Europe with regions of slight decrease in central Finland and southern Poland. The maximum positive (negative) trend within the Baltic catchment amounts to 31.01 $(-14.28) \mathrm{mm} /$ decade (seasonal totals). On average, the Baltic catchment has become wetter by $8.24 \mathrm{~mm} /$ decade. Highest relative rates of change are found over the Baltic states with rates of change up to $20.62 \%$ of 1961-1990 mean per decade, which corresponds roughly to a doubling of the seasonal precipitation during the period under investigation. An overview of the spatial statistics of the relative rates of change for the Baltic catchment based on the changes in CRU is given in Table 2.

It is well known that a part of the precipitation trend, in particular along the Atlantic coastline, is strongly affected by the North Atlantic Oscillation (Lamb and Peppler 1987; Wanner et al. 2001). The NAO signal in wintertime precipitation is a general increase (decrease) in precipitation with increasing (decreasing) NAO index over most parts of the domain under investigation, which is strongest in southern Norway and along the Norwegian coast (not shown). In view of our hypothesis, that the signal-to-noise ratio of anthropogenic climate change in the NAO would be low (Rauthe et al. 2004), we subtracted the NAO signal from the precipitation trends (Fig. 3 left panel). Furthermore, a number of studies conclude that the observed increase in the NAO is at least partially externally forced (Osborn et al. 1999; Gillett et al. 2002; Gillett 2005, among others), but the simulated trend in the NAO is generally smaller than observed (Gillett et al. 2002; Osborn 2004). Excluding the NAO signal thus also excludes a part of the variability from the observations, which is not reproduced by present day climate models. As a consequence, we expect the similarity of the patterns of the observed and simulated changes to increase and the intensities of the changes to converge.

The removal of the NAO signal leads to a considerable reduction in precipitation trends along the west coast of Europe as shown in the right panel of Fig. 3. The spatially averaged 30-year trend over the Baltic catchment decreases by $2.31 \mathrm{~mm} /$ decade when removing the NAO; the largest and smallest trends over the Baltic catchment are also reduced (31.01 vs. $26.47 \mathrm{~mm} /$ decade; -14.28 vs. $-13.74 \mathrm{~mm} /$ decade). Nevertheless, the distribution is smoother (spatial standard deviation $=5.88 \mathrm{~mm} /$ decade) without the NAO than with the NAO $(6.55 \mathrm{~mm} /$ decade $)$. However, in central Finland and in southern parts of the Elbe catchment, subtracting the NAO signal increases the trends. These findings qualitatively apply to wider northern Europe as well.

\subsection{Expected changes derived from climate change scenarios}

Figure 4 shows the anthropogenic climate change projections for winter precipitation as derived from a pair of 30year simulations, namely 2071-2100 and 1961-1990. Apart from the scenarios as introduced in Sect. 2.2, the respective mean change of the scenarios forced with SRES A2 and B2, HadAM and ECHAM as well as the overall mean is shown in Fig. 4. The nine maps are to first order similar with increasing precipitation all over the Baltic catchment and in most of northern Europe. The major difference among the projections is located in an area just outside the Baltic catchment. Along the coastline in northwestern Norway, the HadAM simulations project a decrease in precipitation whereas the experiments driven with the ECHAM model show an increase.

Spatially averaged future changes in the Baltic catchment are larger in the ECHAM driven simulations (7.27 $\mathrm{mm} /$ decade) than in HadAM driven simulations (4.12 mm/decade) as shown in Fig. 4. In accordance with the stronger forcing, the mean response to the A2 emission scenario is higher than the response to B2 (6.59 and 


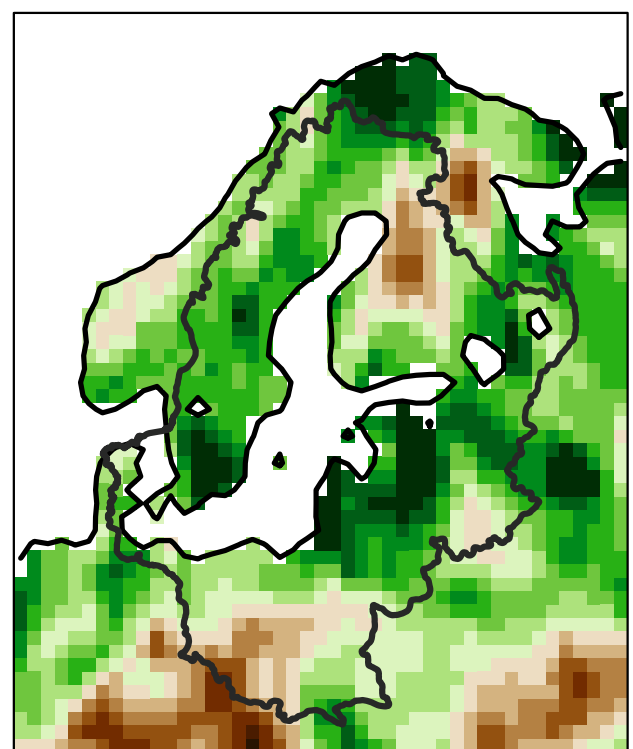

percentage of 1961-1990 mean per decade

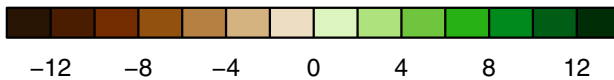

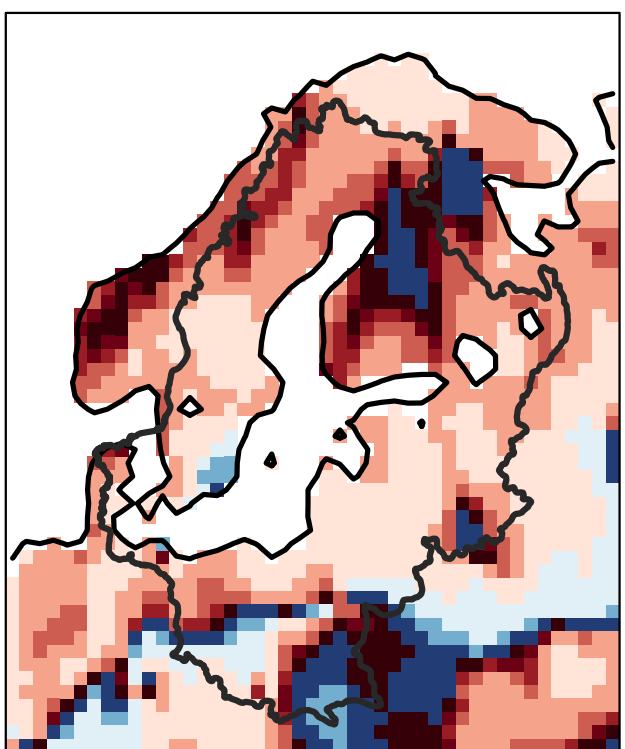

percentage of original trends

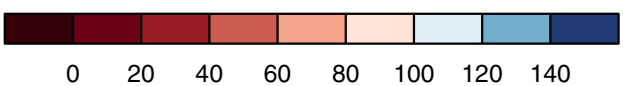

Fig. 3 Left panel Trends in winter (DJF) mean precipitation 1973-2002, according to the CRU TS 2.1 data after the removal of the NAO signal. Right panel percentage of trend after the removal of the NAO signal compared to the full trend shown in Fig. 2

$4.80 \mathrm{~mm} /$ decade). Additionally, it is found that the spatial standard deviation of HadAM trends is lower (1.56 and $0.76 \mathrm{~mm} /$ decade for A2 and B2) than the standard deviation of the ECHAM simulations $(2.38$ and 1.39 , respectively).

We have further assessed the significance of the projected anthropogenic change according to the regional model simulations. It is shown that for most of the region under consideration, the anthropogenic signal is hardly describable as a result of internal model variability. For the Baltic catchment, all of the changes as projected in the ECHAM driven runs have found to be significant at the five-percent level (one-sided $t$ test taking into account autocorrelation, see Sect. 2.4), whereas the fraction of significant changes is $97.7 \%$ (96.6\%) for HadAM A2 (B2).

Extending the research domain to all of northern Europe decreases the amount of grid boxes where the projections are significantly different from internal climate variability. Significant changes are found for 93.4 (90.9) percent of all land grid points in HadAM A2 (B2) and 90.7 (94.7) percent in ECHAM A2 (B2). As shown in Fig. 4, the regions where the projections are not significantly different from internal variability are located on the northwestern coast of Norway and Finland in the HadAM driven simulations, whereas insignificant changes are found in the southeastern part of northern Europe in the ECHAM driven simulations.
The similarity of the different climate change projections has been assessed using pattern correlation as introduced in Sect. 2.4. As the observation data are available over land only, the PCCs between individual projections have been calculated using land grid boxes only as well. All of the climate change projections share very high PCCs of 0.941 (HadAM B2 with ECHAM A2) to 0.996 (ECHAM A2 with B2) for the Baltic catchment. When the area of interest is extended to wider northern Europe, the PCCs of projections driven with different GCMs are considerably reduced (0.831-0.928), whereas the patterns of simulations with different emission forcings with the same GCM are very similar with PCCs larger than 0.98 .

Furthermore, the NAO signal has been removed from the simulations and climate change signals have been computed from the residuals. A consistent increase in the NAO index is found for all simulations. This change in the NAO index is stronger in the ECHAM simulations, with an increase in the difference between the normalized SLP series of the grid box Gibraltar and Reykjavik of 0.39 (0.61) per 110 years in the A2 (B2) simulation, than in the HadAM driven ones with an increase of $0.22(0.20)$. The NAO signal in the simulations (not shown) is very similar to the NAO signal in the observations (e.g. Fig. 3), with increasing (decreasing) precipitation in northwestern Europe with increasing (decreasing) NAO index (not shown). 
Fig. 4 Anthropogenic climate change signal in DJF precipitation according to RCAO simulations with the four individual climate change projections in the upper left four panels and the respective mean of simulations driven with the same GCM (same emission scenario) in the bottom line (rightmost column). The hatched areas denote regions where the climate change projections are not significant at the 5\% level (see Sect. 2.2 for details); in the bottom line and rightmost column, areas where the projection of at least one of the four projections is not significant are hatched
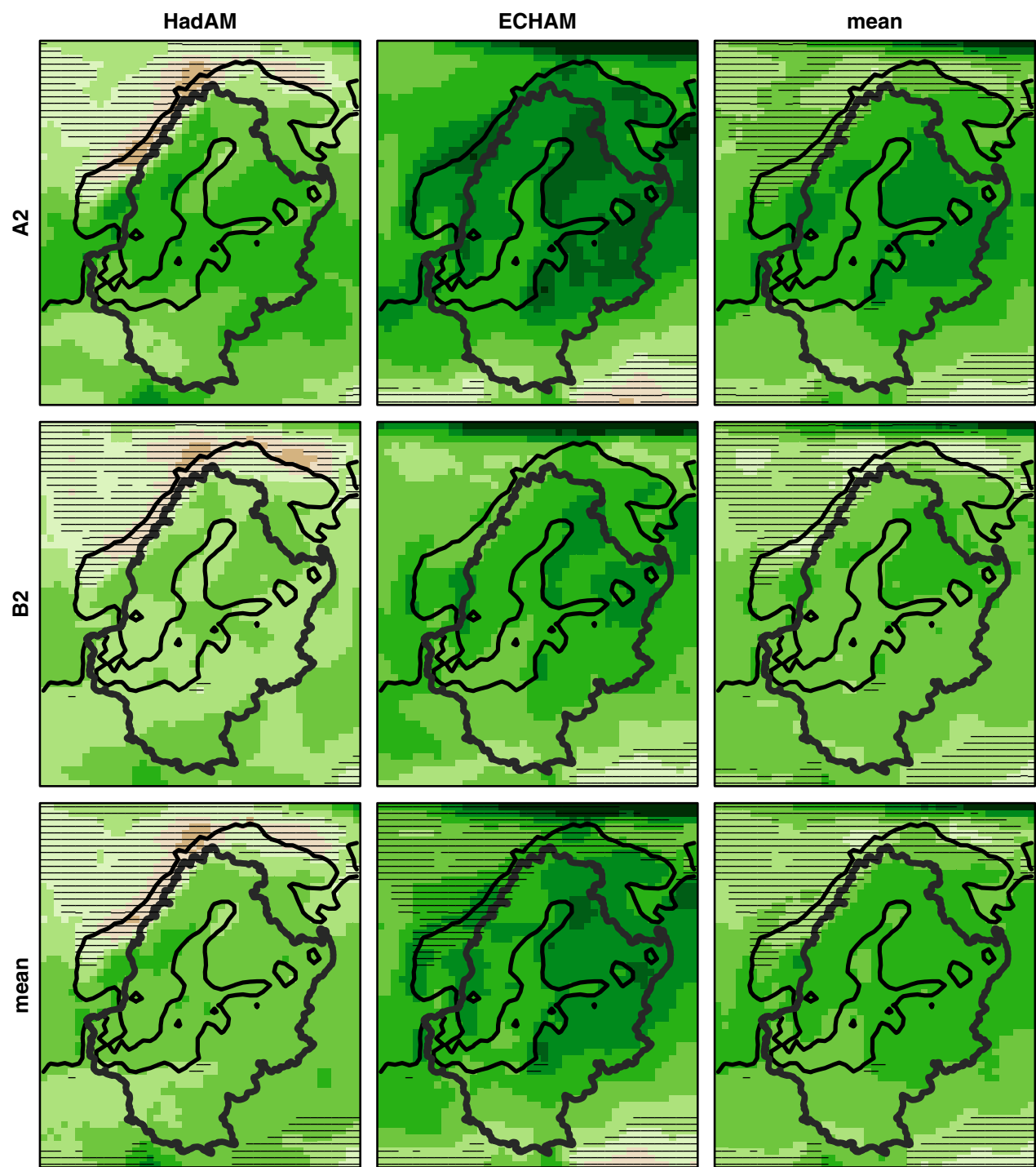

percentage of 1961-1990 mean per decade

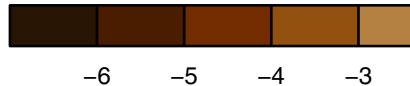

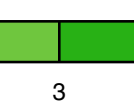

Table 3). In general, the pattern of observed trends shows more similarity with the ECHAM driven simulations than with HadAM ones. Furthermore, the stronger greenhouse gas forcing (SRES A2 scenario) leads to higher pattern correlation scores. Highest pattern similarity $(0.85$ for the

Table 3 Spatial statistics of the observed and expected changes (in units of percentage change of the respective 1961-1990 mean per decade) for the Baltic catchment

\begin{tabular}{lll}
\hline & CRU & Range of RCAO scenarios \\
\hline Spatial mean & $6.97(4.97)$ & $1.89-4.38(1.79-3.70)$ \\
Spatial std & $5.27(4.90)$ & $0.42-0.97(0.63-1.55)$ \\
Intensity & $8.73(6.98)$ & $1.94-4.49(1.90-4.01)$ \\
\hline
\end{tabular}

Values in brackets refer to the spatial statistics for the Baltic catchment after removing the NAO signal

Significant (bootstrap test, $5 \%$ ) results are labelled with an asterisk 
Baltic catchment, 0.80 for northern Europe) is thus found when comparing the observed trends with the ECHAM A2 simulation.

The observed PCCs based on the Baltic catchment all lie above the 95th percentile according to the bootstrap introduced in Sect. 2.4. This is not the case when extending the research area to all of northern Europe. The PCCs of the observed trends and ECHAM driven regional model simulations are significantly different from random PCCs whereas PCCs based on HadAM A2 lie close to and PCCs based on HadAM B2 lie below the 95th percentile of random PCCs.

The removal of the NAO signal leads to slightly different trend patterns in the observations (as illustrated in Fig. 3) and in the climate change projections (not shown). In general, this causes a reduction of the PCCs which is most pronounced for the HadAM B2 simulation (reduction of $15 \%$, Table 3 ). In combination with the slightly higher significance levels when removing the NAO, PCCs are less often significantly different from random pattern correlation. For the Baltic catchment the pattern similarity is significant at the 5\% level for all projections except the HadAM B2 scenario, whereas the PCCs for northern Europe fail to be significantly different from randomly generated PCCs for both HadAM simulations.

As a consequence of the normalization of the PCC by the intensities, no conclusions can be drawn about the similarity of the magnitude of the changes with pattern correlation. Therefore, we further compare the spatial mean change and the intensity of the change (Table 2). In order to account for systematic biases between model and observation data, we compare relative changes only. It is found that the changes in HadAM simulations are weaker than in ECHAM simulations and in accordance with the weaker GHG forcing in the SRES B2 driven projections weaker than in simulations run with SRES A2. Thus leading to an area mean change of 1.89 (HadAM B2) to $4.38 \%$ per decade (with respect to the 1961-1990 mean) for the Baltic catchment. The spatial mean change in the observation data is considerably higher with $6.97 \%$ per decade for CRU for the period 1973-2002. The discrepancy between the climate change scenarios and observed changes is even larger when looking at the intensity of the change, and thus taking the spatial variability of the trend fields into account as well. For wider northern Europe, the spatial statistics show qualitatively similar features (not shown).

When looking at the spatial statistics after removing the NAO signal from the data, we find the following. As discussed in Sect. 3.1, the removal of the NAO leads to a considerable reduction in the spatial mean trends for the period from 1973 to 2002 . As the removal affects mainly the spatial mean trend, the intensities are still much higher in the observations after removing the NAO signal than in the climate change scenarios.

Both PCCs as well as the intensities are computed limited to regions of significant change in the climate change projections as well. The effect on the results for the Baltic catchment is negligible as only very few grid points are excluded from the analysis. For northern Europe, however, we find a considerable increase in pattern similarity statistics which is more pronounced for the HadAM projections than for projections driven with ECHAM. Weakest pattern similarity is still found when comparing the observations with HadAM B2. Focussing on regions with significant changes leads to a slight increase in the intensities of the climate change projections and thus decreases the ratio of intensities.

\section{Discussion}

\subsection{Methodical considerations}

It is shown that PCCs are sensitive to both the magnitude of the mean change and the pattern of the change as an extension of the analysis from the Baltic catchment to all of northern Europe and the comparison of results with A2 and B2 emission scenarios show. Thus we conclude, that the method is illustrative even in situations where the climate change scenarios deviate to some extent.

\subsection{Regional climate change scenarios}

We use a set of climate change projections in our analysis indicating the range of the response to anthropogenic forcing. A priori, we consider all of the individual projections as possible and equally likely. The projected signal for the Baltic catchment is fairly consistent in both magnitude and pattern taking into account the differences in GHG forcing for the $\mathrm{A} 2$ and $\mathrm{B} 2$ scenarios (e.g. $\mathrm{CO}_{2}$ induced radiative forcing of $4.42(2.73) \mathrm{W} / \mathrm{m}^{2}$ in 2100 with respect to 2000 for the SRES A2 (B2) scenario, Ramaswamy et al. 2001). However, there are still large discrepancies in the way different GCMs model the response of circulation (and as a consequence precipitation as well) to anthropogenic forcing as illustrated by the situation along the Norwegian coast.

\subsection{Comparison of observed and simulated changes}

\subsubsection{Pattern correlation}

The pattern of observed trends in winter precipitation in the Baltic catchment has been found to be consistent with all of 
the regional climate change scenarios used in this analysis (Table 3). Furthermore, it is very improbable (with a probability of error of less than $5 \%$ ) that the correlation found between patterns of observed and expected changes is random. This holds true for northern Europe as well, however, the observed patterns are considerably less consistent with the HadAM driven scenarios, due to a completely different response in some parts of northern Europe compared with the ECHAM scenarios. Even though the scenarios differ much more when extending the research area from the Baltic catchment to northern European land areas, we conclude that the recently observed pattern of change is consistent with the climate change scenarios at least for the projections driven with ECHAM.

Above findings are strengthened when limiting the analysis to regions where the changes in the scenarios have been found to be significant according to an adjusted $t$ test. The exclusion of regions with insignificant climate change projections increases the signal-to-noise ratio of anthropogenic change (assuming that the climate models are able to model both the natural variability and the response to anthropogenic forcing correctly) and thus it is not surprising that we find better consistency between the modelled response and observed changes. Furthermore, the differences in consistency between HadAM and ECHAM driven simulations for northern Europe vanishes, as the regions with insignificant changes in the projections are in this case identical to the regions where the climate change scenarios differ most.

Further insight is gained when removing the NAO signal from both the observations and the climate change simulations. The correspondence of the changes in the residuals is considerably lower than in the full set, and we conclude consistency between observed and projected changes only for ECHAM driven scenarios (and HadAM A2 as well for the Baltic catchment).

The hypothesis that the signal-to-noise ratio of anthropogenic change in the NAO would be low is discussed in the following. The projected increase in the NAO index from 1961-1990 to 2071-2100 ranges from 0.2 in the HadAM simulations to 0.38 (0.61) in ECHAM A2 (B2). Thus, a consistent increase is shown among all four climate change projections, which is in line with the findings of Stephenson et al. (2006). However, the increase is significant on the five-percent level for the ECHAM B2 scenario only according to a $t$ test as introduced in Sect. 2.4. Thus most of the changes in the NAO in the set of model simulations could be due to internal variability alone, which in turn supports the basic assumption that the signal-to-noise ratio of anthropogenic change in the NAO is low. In opposition to these findings, Gillett et al. (2002) find that the response of the NAO to GHG forcing in both the ECHAM4 and HadCM3 (a coupled version of the model used to drive the RCM simulations used in this study) is not explicable by internal variability alone. This discrepancy could result from differences in the definition of the NAO index; Osborn (2004) shows that the response to GHG forcing is much more model dependent when using a station based NAO index compared to pattern based indices.

Additionally, the considerable differences between ECHAM and HadAM driven simulations point again towards a different response of circulation to anthropogenic forcing in these models. Furthermore, it is interesting to see that the stronger greenhouse gas forcing leads to a weaker increase in the NAO in the ECHAM driven scenarios. This could either be a consequence of a nonlinear response to the imposed forcing or due to the dominance of natural variability in the NAO estimates.

The observed trend in the NAO index of Jones et al. (1997) from 1973 to 2003 is 0.292 per decade. Thus, the projected increase in the NAO index amounts to $6-19 \%$ of the observed trend in the NAO only. It is a well-known fact that present day climate models underestimate the variability of the NAO and presumably also the response to increasing GHG (Osborn 2004; Stephenson et al. 2006). Thus we conclude that either the projections of the NAO increase are correct and hence the signal-to-noise ratio of anthropogenic change in the NAO is low, or the response of the NAO to increasing GHG is stronger than simulated. The latter would have severe consequences for all conclusions drawn from these regional climate change projections as a stronger response of the NAO to GHG forcing would very likely lead to a stronger response of precipitation as well.

\subsubsection{Magnitude of the rate of change}

When comparing the spatial mean change, we find that the models underestimate the most recent rate of change by a factor of 1.4 (ECHAM A2) to 3.3 (HadAM B2) for the Baltic catchment. The same applies for all of northern Europe as well. In contrast, when removing the NAO signal, we find considerably better agreement of the observed area mean change with the climate change projections. Nevertheless, it is shown that the climate change simulations generally underestimate the observed change. Whether this mismatch in magnitude of the area mean changes is in any way significant is hard to infer from the data at hand. With respect to uncertainties in the observation data and interpolation, further experiments have shown, that for the Baltic catchment, the most recent area mean trends are significantly (with a probability of alphatype error of 5\%) different from the estimated area mean response when adding white noise with a standard deviation of 5.6\% of the respective 1961-90 mean. However, as 
systematic biases have not been removed from the data (New et al. 1999; Mitchell and Jones 2005) the error mainly due to wind-induced undercatch could be larger (Adam and Lettenmaier 2003; Yang et al. 2005). Furthermore, the robustness of the conclusions to a shift of the period analyzed has been investigated. For the Baltic catchment area mean changes we find that 8 (11) of the last 10 (20) 30-year trends available are higher than the topmost anthropogenic change estimate (ECHAM A2). Whether these results indicate an emerging anthropogenic signal or fluctuations due to natural variability cannot be inferred. Finally, it should be noted that even though we analyze relative precipitation changes, and thus systematic biases between the simulated and observed precipitation have little influence on the result, modelling deficiencies could severely influence the conclusions drawn.

As mentioned before, given all assumptions are correct, there are three possible reasons for this mismatch in the spatial mean change.

First of all, it could be due to the fact that the regional models are not able at all to simulate the response to anthropogenic forcing.

Second, the models could severely underestimate the response because more than the imposed forcing is at work or because the sensitivity to anthropogenic forcing is far to low. Gillett et al. (2004) and Zhang et al. (2007) all conclude that the GCMs used in their global-scale detection and attribution studies considerably underestimate the response of circulation and precipitation to external forcing. However, Lambert et al. (2004) also find a strong influence of volcanic forcing. In contrast to the studies mentioned above, our simulations include anthropogenic changes only, thus we should keep in mind, that the response to natural forcing could be dominant in the observations. Apart from changes in aerosols due to volcanic eruptions, the main candidate for an additional forcing mechanism which could have a large effect on regional circulation and precipitation are industrial aerosols. According to (Räisänen et al. 2004), the ECHAM and the HadAM model both include changes in global scale aerosol concentrations, and treat the contribution to the radiative forcing explicitly. Furthermore, they argue, that the RCAO is not very sensitive to local changes in radiative forcing, since most of the climate change signal comes via the boundary conditions from the GCMs. However, mainly the indirect aerosol effect could cause strong and smallscale response in precipitation (Ramanathan et al. 2001) not captured in the models yet. Additionally, the scientific understanding of both the direct and indirect aerosol effects is still considered medium to low (Forster et al. 2007), and thus there is ample room for speculation.

Third, the signal-to-noise ratio of anthropogenic precipitation change is very small. Assuming that the model projections are right in both intensity and pattern, we conclude the following: a large fraction of the recent 30-year trends in wintertime precipitation are due to natural variability. The removal of the NAO signal leads to a considerable decrease in the ratio of the intensities as shown in Table 2. Thus, by excluding the NAO signal we increase the signal-to-noise ratio, which in turn supports the basic assumption, that the signal-to-noise ratio in the NAO is low.

Looking at the intensity of the change, and thus taking the spatial variability of the changes into account as well, the difference between observations and climate change simulations increases. Whether this is due to the fact that the climate change signal is large scale, and thus exhibits only little spatial variability over a small domain, cannot be determined. Alternatively, the different spatial scales represented in the gridded observations compared to the scales modelled in the RCM setup, could account for the difference in intensity as well.

\section{Conclusions}

Our analyses have shown that pattern correlation along with a comparison of the intensity of the changes as presented in this paper is suitable to assess the consistency of observed trends with climate change projections. The method as presented here is also applicable when natural variability estimates are missing and thus it is very useful when investigating climatic parameters for which longterm observations are not available and which are statistically less well behaved than surface temperature.

According to pattern correlation studies, anthropogenic forcing is a plausible explanation of the observed changes in wintertime precipitation over the Baltic catchment. Bootstrap experiments also show that it is unlikely that these pattern correlations are random. The situation is a little different when extending the area of interest to all of northern Europe. In this larger area, the climate model simulations project less consistent changes and consequently PCCs are only significantly different from random PCCs for some of the simulations. Thus the selection of the region under consideration has a great effect on the result. However, it is encouraging that we find consistency of the observed trends with regional climate change scenarios in regions where the different simulations project a consistent and significant change and less so in regions where the climate change scenarios differ.

The magnitude of the observed area mean change, however, is higher than the magnitudes as projected by the regional climate model. Hence, we cannot explain the observed trends in winter precipitation with increasing greenhouse gases alone. Both additional forcing mechanisms (such as the indirect aerosol effect) not included 
in this model setup, and a general underestimate of the response to anthropogenic forcing are possible explanations for the mismatch in the rate of change. Additionally, another important factor possibly contributing to the trends in the observation data is natural variability, the importance of which cannot be inferred using the approach introduced here.

Acknowledgments This study contributes to the GEWEX-BALTEX programme. The regional climate model simulations have been provided through the PRUDENCE data archive, funded by the EU through contract EVK2-CT2001-00132. The gridded precipitation observations have been provided by the Climatic Research Unit. We thank Gabi Hegerl and an anonymous reviewer for valuable comments on the manuscript.

Open Access This article is distributed under the terms of the Creative Commons Attribution Noncommercial License which permits any noncommercial use, distribution, and reproduction in any medium, provided the original author(s) and source are credited.

\section{References}

Adam JC, Lettenmaier DP (2003) Adjustment of global gridded precipitation for systematic bias. J Geophys Res 108:4257

Allen MR, Tett SFB (1999) Checking for model consistency in optimal fingerprinting. Clim Dyn 15:419-434

BACC author team (2008) Assessment of climate change for the Baltic Sea Basin. Regional climate studies. Springer, Berlin p 474

Barnett T, Zwiers F, Hegerl G, Allen M, Crowley T, Gillett N, Hasselmann K, Jones P, Santer B, Schnur R, Scott P, Taylor K, Tett S (2005) Detecting and attributing external influences on the climate system: a review of recent advances. J Clim 18:12911314

Cubasch U, Meehl G, Boer G, Stouffer R, Dix M, Noda A, Senior C, Raper S, Yap K (2001) Projections of future climate change. In: Houghton J, Ding Y, Griggs D, Noguer M, van der Linden P, Dai X, Maskell K, Johnson C (eds) Climate change 2007: the physical science basis. Contribution of Working Group I to the third assessment report of the Intergovernmental Panel on Climate Change. Cambridge University Press, Cambridge, pp 99-181

Forster P, Ramaswamy V, Artaxo P, Berntsen T, Betts R, Fahey D, Haywood J, Lean J, Lowe D, Myhre G, Nganga J, Prinn R, Raga G, Schulz M, Dorland RV (2007) Changes in atmospheric constituents and in radiative forcing. In: Solomon S, Qin D, Manning M, Chen Z, Marquis M, Averyt K, MTignor, Miller H (eds) Climate change 2007: the physical science basis. Contribution of Working Group I to the fourth assessment report of the Intergovernmental Panel on Climate Change. Cambridge University Press, Cambridge, pp 129-234

Gillett NP (2005) Northern hemisphere circulation. Nature 437:496496

Gillett NP, Allen MR, McDonald RE, Senior CA, Shindell DT, Schmidt GA (2002) How linear is the arctic oscillation response to greenhouse gases? J Geophys Res 107:4022

Gillett NP, Weaver AJ, Zwiers FW, Wehner MF (2004) Detection of volcanic influence on global precipitation. Geophys Res Lett 31, L12217. doi:10.1029/2004GL020044

Gordon C, Cooper C, Senior CA, Banks H, Gregory JM, Johns TC, Mitchell JFB, Wood RA (2000) The simulation of SST, sea ice extents and ocean heat transports in a version of the Hadley Centre coupled model without flux adjustments. Clim Dyn 16:147-168

Hasselmann K (1993) Optimal fingerprints for the detection of timedependent climate-change. J Clim 6:1957-1971

Hasselmann K (1997) Multi-pattern fingerprint method for detection and attribution of climate change. Clim Dyn 13:601-611

Hegerl G, Zwiers FW, Braconnot P, Gillett N, Luo Y, Orsini JM, Nicholls N, Penner J, Stott P (2007) Understanding and attributing climate change. In: Solomon S, Qin D, Manning M, Chen Z, Marquis M, Averyt K, Tignor M, Miller H (eds) Climate change 2007: the physical science basis. Contribution of Working Group I to the fourth assessment report of the Intergovernmental Panel on Climate Change. Cambridge University Press, Cambridge, pp 663-745

Jones PD, Jonsson T, Wheeler D (1997) Extension to the North Atlantic Oscillation using early instrumental pressure observations from Gibraltar and south-west Iceland. Int J Climatol 17:1433-1450

Kjellström E (2004) Recent and future signatures of climate change in Europe. Ambio 33:193-198

Lamb PJ, Peppler RA (1987) North-Atlantic Oscillation-concept and an application. Bull Am Meteorol Soc 68:1218-1225

Lambert FH, Stott PA, Allen MR, Palmer MA (2004) Detection and attribution of changes in 20th century land precipitation. Geophys Res Lett 31, L10203. doi:10.1029/2004GL019545

Mitchell TD, Jones PD (2005) An improved method of constructing a database of monthly climate observations and associated highresolution grids. Int J Climatol 25:693-712

New M, Hulme M, Jones P (1999) Representing twentieth-century space-time climate variability. part i: Development of a 1961-90 mean monthly terrestrial climatology. J Clim 12:829-856

Osborn TJ (2004) Simulating the winter North Atlantic Oscillation: the roles of internal variability and greenhouse gas forcing. Clim Dyn 22:605-623

Osborn TJ, Briffa KR, Tett SFB, Jones PD, Trigo RM (1999) Evaluation of the north atlantic oscillation as simulated by a coupled climate model. Clim Dyn 15:685-702

Räisänen J, Hansson U, Ullerstig A, Döscher R, Graham LP, Jones C, Meier HEM, Samuelsson P, Willén U (2004) European climate in the late twenty-first century: regional simulations with two driving global models and two forcing scenarios. Clim Dyn 22:13-31

Ramanathan V, Crutzen PJ, Kiehl JT, Rosenfeld D (2001) Aerosols, climate, and the hydrological cycle. Science 294:2119-2124

Ramaswamy V, Boucher O, Haigh J, Hauglustaine D, Haywood J, Myhre G, Nakajima T, Shi G, Solomon S (2001) Radiative forcing of climate change. In: Houghton J, Ding Y, Griggs D, Noguer M, van der Linden P, Dai X, Maskell K, Johnson C (eds) Climate change 2007: the physical science basis. Contribution of Working Group I to the third assessment report of the Intergovernmental Panel on Climate Change. Cambridge University Press, Cambridge, pp 99-181

Rauthe M, Hense A, Paeth H (2004) A model intercomparison study of climate change-signals in extratropical circulation. Int $\mathrm{J}$ Climatol 24:643-662

Roeckner E, Bengtsson L, Feichter J, Lelieveld J, Rodhe H (1999) Transient climate change simulations with a coupled atmosphere-ocean GCM including the tropospheric sulfur cycle. J Clim 12:3004-3032

Santer BD, Wigley TML, Jones PD (1993) Correlation methods in fingerprint detection studies. Clim Dyn 8:265-276

Spagnoli B, Planton S, Déqué M, Mestre O, Moisselin JM (2002) Detecting climate change at a regional scale: the case of France. Geophys Res Lett 29(10). doi:10.1029/2001GL014619 
Stephenson DB, Pavan V, Collins M, Junge MM, Quadrelli R (2006) North Atlantic Oscillation response to transient greenhouse gas forcing and the impact on European winter climate: a CMIP2 multi-model assessment. Clim Dyn 27:401-420

Stott PA (2003) Attribution of regional-scale temperature changes to anthropogenic and natural causes. Geophys Res Lett 30

Stott PA, Tett SFB (1998) Scale-dependent detection of climate change. J Clim 11:3282-3294

Wanner H, Brönnimann S, Casty C, Gyalistras D, Luterbacher J, Schmutz C, Stephenson DB, Xoplaki E (2001) North Atlantic Oscillation-concepts and studies. Surv Geophys 22:321-382

Wilks DS (1997) Resampling hypothesis tests for autocorrelated fields. J Clim 10:65-82
Yang DQ, Kane D, Zhang ZP, Legates D, Goodison B (2005) Bias corrections of long-term (1973-2004) daily precipitation data over the northern regions. Geophys Res Lett 32, L19501. doi: 10.1029/2005GL024057

Zhang X, Zwiers F, Hegerl GC, Lambert FH, Gillett NP, Solomon S, Stott PA, TN (2007) Detection of human influence on twentiethcentury precipitation trends. Nature 448:461-465

Zwiers FW, von Storch H (1995) Taking serial-correlation into account in tests of the mean. J Clim 8:336-351

Zwiers FW, Zhang XB (2003) Toward regional-scale climate change detection. J Clim 16:793-797 